\title{
Complex translocation disrupting TCF4 and altering TCF4 isoform expression segregates as mild autosomal dominant intellectual disability
}

Valerie Maduro', Barbara N. Pusey ${ }^{1}$, Praveen F. Cherukuri ${ }^{1}$, Paul Atkins ${ }^{2,3}$, Christèle du Souich ${ }^{2,3}$, Rosemarie Rupps ${ }^{2,3}$, Marjolaine Limbos ${ }^{4}$, David R. Adams' ${ }^{1}$, Samarth S. Bhatt ${ }^{5}$, Patrice Eydoux ${ }^{6}$, Amanda E. Links' ${ }^{1}$ Anna Lehman ${ }^{2,3}$, May C. Malicdan ${ }^{1}$, Christopher E. Mason ${ }^{7,8,9}$, Marie Morimoto ${ }^{2,3}$, James C. Mullikin ${ }^{10}$, Andrew Sear ${ }^{11}$, Clara Van Karnebeek ${ }^{3}$, Pawel Stankiewicz ${ }^{5}$, William A. Gahl ${ }^{1,12}$, Camilo Toro ${ }^{1}$ and Cornelius F. Boerkoel ${ }^{1,2,3^{*}}$

\begin{abstract}
Background: Mutations of TCF4, which encodes a basic helix-loop-helix transcription factor, cause Pitt-Hopkins syndrome (PTHS) via multiple genetic mechanisms. TCF4 is a complex locus expressing multiple transcripts by alternative splicing and use of multiple promoters. To address the relationship between mutation of these transcripts and phenotype, we report a three-generation family segregating mild intellectual disability with a chromosomal translocation disrupting TCF4.
\end{abstract}

Results: Using whole genome sequencing, we detected a complex unbalanced karyotype disrupting TCF4 (46,XY,del(14)(q23.3q23.3)del(18)(q21.2q21.2)del(18)(q21.2q21.2)inv(18)(q21.2q21.2)t(14;18)(q23.3;q21.2)(14pter ${ }^{\circledR}$

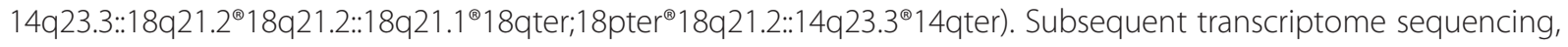
qRT-PCR and nCounter analyses revealed that cultured skin fibroblasts and peripheral blood had normal expression of genes along chromosomes 14 or 18 and no marked changes in expression of genes other than TCF4. Affected individuals had 12-33 fold higher mRNA levels of TCF4 than did unaffected controls or individuals with PTHS. Although the derivative chromosome generated a PLEKHG3-TCF4 fusion transcript, the increased levels of TCF4 mRNA arose from transcript variants originating distal to the translocation breakpoint, not from the fusion transcript.

Conclusions: Although validation in additional patients is required, our findings suggest that the dysmorphic features and severe intellectual disability characteristic of PTHS are partially rescued by overexpression of those short TCF4 transcripts encoding a nuclear localization signal, a transcription activation domain, and the basic helix-loop-helix domain.

Keywords: Intellectual disability, Promoter utilization, Pitt-Hopkins syndrome, TCF4, Gene expression, Translocation, Transcriptome, RNAseq

\footnotetext{
* Correspondence: cboerkoel@gmail.com

${ }^{1} \mathrm{NIH}$ Undiagnosed Diseases Program, Common Fund, Office of the Director,

National Institutes of Health, Bethesda, MD, USA

Department of Medical Genetics, University of British Columbia, Children's

and Women's Health Centre of BC, Vancouver, BC, Canada

Full list of author information is available at the end of the article
}

\section{Ciomed Central}

(C) 2016 Maduro et al. Open Access This article is distributed under the terms of the Creative Commons Attribution 4.0 International License (http://creativecommons.org/licenses/by/4.0/), which permits unrestricted use, distribution, and reproduction in any medium, provided you give appropriate credit to the original author(s) and the source, provide a link to the Creative Commons license, and indicate if changes were made. The Creative Commons Public Domain Dedication waiver (http://creativecommons.org/publicdomain/zero/1.0/) applies to the data made available in this article, unless otherwise stated. 


\section{Background}

Intellectual disability (ID) is characterized as a significant deficit in intellectual functioning and in adaptive, conceptual, practical, and social skills [1], beginning before the age of 18 years. Depending on the ascertainment methodology and definition, the prevalence of ID in the general population is $1-3 \%$ in industrialized countries [2-5].

Despite the prevalence and morbidity of ID, its physiologic bases remain poorly understood. Identified causes include environmental, epigenetic, and genetic factors [6, 7]. At a cellular level, these factors affect neuronal proliferation, migration, arborization, synaptogenesis, function, or viability [7-9].

Normal brain development involves the precise orchestration of several processes. Derailment of these processes by either a genetic or environmental insult causes cognitive and other neurodevelopmental disorders. Consistent with neurodevelopment being highly dependent on the choreographed expression of genes regulating neuronal development, an increasing number of cognitive disorders have been recently recognized to be attributable to mutations in regulators of gene expression [10-14].

Among the mutated chromatin regulators and transcription factors associated with ID is transcription factor 4 (TCF4). TCF4 is transcribed from multiple promoters and alternative splice transcripts resulting in at least 18 different protein isoforms [15]. TCF4, via its interactions with other proteins, modulates an intricate combinatorial regulatory circuit during central nervous system (CNS) development [16]. Several splice variants show differential subcellular distribution [15]. TCF4 encodes for class I basic helix-loop-helix (bHLH) proteins that function as transcriptional regulators when they heterodimerize with tissue-restricted class II bHLH proteins [17].

Class II bHLH transcription factors co-expressed or interacting with TCF4 during neurodevelopment include Math1, a proneural protein expressed in the differentiating neuroepithelium [18-20]; HASH1, a protein necessary for the formation of distinct neuronal circuits within the CNS, especially the telencephalon [21]; neuroD2, which plays important roles in neuronal differentiation and survival [22]; Id1, which is a homolog of proteins required for correct patterning in neurogenesis [23]; and Olig2, a regulator of ventral neuroectodermal progenitor cell fate [24-26].

Mono-allelic mutations or genomic deletions of TCF4 cause Pitt-Hopkins syndrome (PTHS) [27-30]. PTHS has an estimated prevalence of 1 in 34,000 to 1 in 41,000 [31] and is characterized by severe ID, facial dysmorphism, episodes of hyperventilation, acquired microcephaly, seizures, happy disposition, and repetitive movements.

Analysis of the functional consequences of PTHSassociated TCF4 mutations has found that not all deletions and truncations of TCF4 result in complete loss-offunction. Also, reading-frame elongating and missense mutations can cause a range of outcomes from subtle functional deficiencies to dominant-negative effects [30]. Consequently, PTHS-associated mutations variably impair the functions of TCF4 by diverse mechanisms and thereby contribute to the phenotypic variability. Herein, we further characterize the phenotypic variability and better define the molecular mechanisms underlying the ID associated with a balanced translocation interrupting TCF4 and segregating with mild ID in three generations.

\section{Subjects \\ Human subjects}

The individuals or guardians of the individuals participating in this study gave informed consent approved by the Institutional Review Board (protocol 76-HG-0238) of the National Human Genome Research Institute. Two individuals with classic features of PTHS provided control blood and/or skin biopsy samples. They were a 14-yearold boy (UDP_10086; PTHS-1) with the mutation NM_00 1083962.1:c. [1650-1 G>A];[=], an established cause of PTHS and a splice acceptor mutation likely causing skipping of exon 18 and encoding p.Ser550Argfs*84 [32], and a 7-year-old girl (UDP_499; PTHS-2) with the mutation NM_001083962.1 (TCF4):c.[1726 C > T]; [=] that encodes p.Arg576\%.

\section{Clinical report}

The proband (UDP_4765; III-3, Fig. 1a) was born to nonconsanguineous parents of mixed European descent and with a family history of miscarriages and intellectual disability. Exposures during the pregnancy included venlafaxine, a serotonin-norepinephrine reuptake inhibitor, and approximately 10 cigarettes per day. The proband was born at term following an uncomplicated pregnancy by spontaneous vaginal delivery. His birth weight, length and head circumference were $4.1 \mathrm{~kg}$ (92nd centile), $54.5 \mathrm{~cm}$ (99th centile), and $35 \mathrm{~cm}$ (66th centile), respectively. His Apgar scores were 9 at 1, 5 and $10 \mathrm{~min}$. There were no neonatal complications or health problems during the first year of life.

At age 14 months, his parents noted delayed development. He scooted at about 12 months and walked without support at $18 \frac{1}{2}$ months. At the age of 2 years, he had 5 meaningful words and communicated predominantly by showing displeasure. At 27 months, his skills were at the level of a 15 to 18 month old; autism spectrum was ruled out. At 4 years 4 months, assessment with the Wechsler Preschool and Primary Scales of Intelligence - Third Edition (WPPSI-III) and Vineland Adaptive Behaviour Scale - Second Edition (Vineland-II), Survey Interview Form showed an uneven profile for verbal, nonverbal and language skills ranging from average to below average. His overall intellectual and adaptive functioning were below average for his age. 


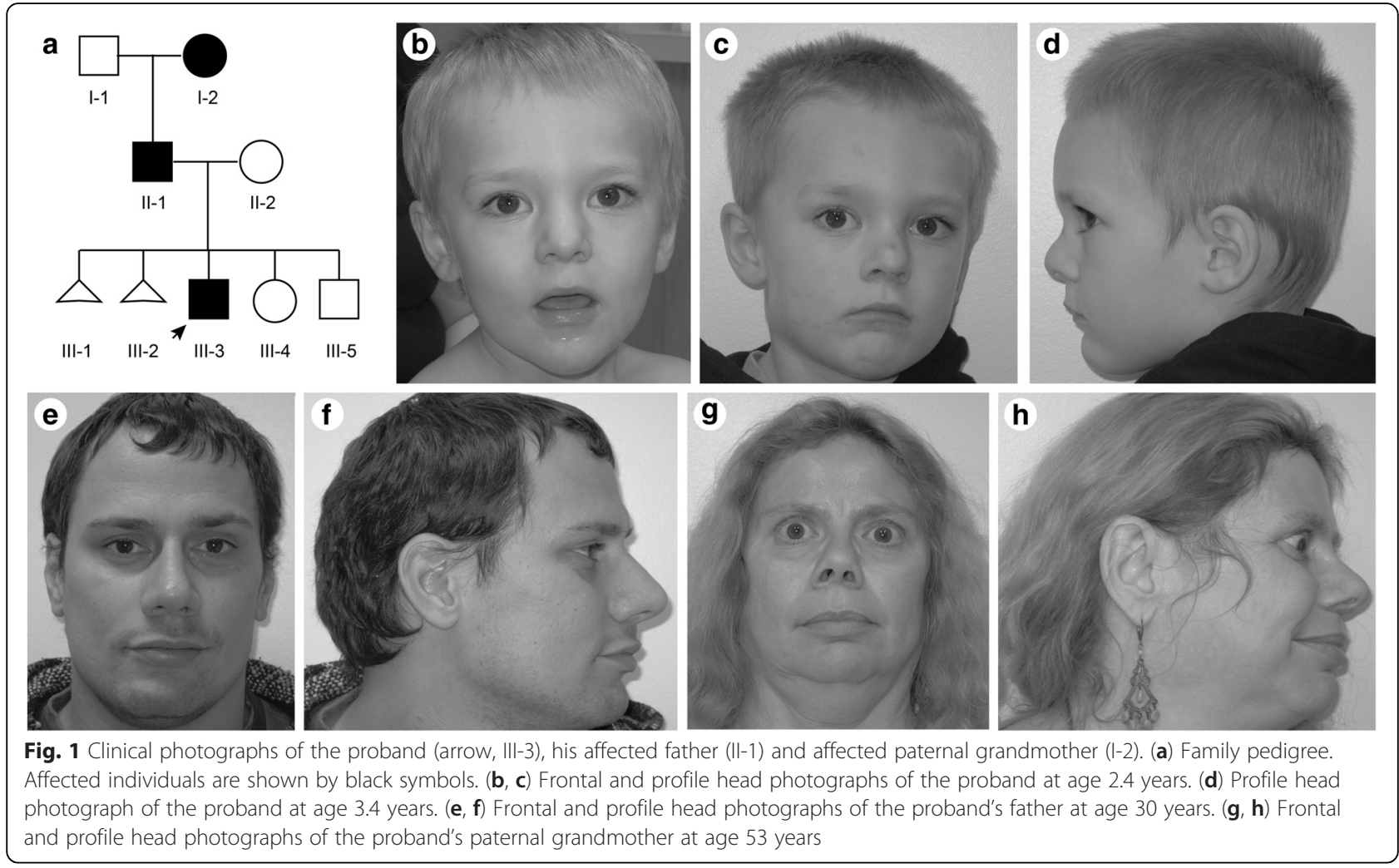

On physical examination at 28 months of age, he had diminished social interaction and had a height of $97.5 \mathrm{~cm}$ (98th centile), a weight of $15 \mathrm{~kg}$ (90th centile), and a head circumference of $50 \mathrm{~cm}$ (82nd centile). His dysmorphic features included plagio- and brachycephaly, prominent glabella, high anterior hairline, hypertelorism, upslanting palpebral fissures, bilateral epicanthal folds, bulbous nasal tip, prominent columella, large $(6.0 \mathrm{~cm}$, 97th centile) cupped ears with a simple helix, a high arched palate, a prominent chin, mildly hypoplastic zygomatic arch, and a pectus carinatum (Fig. 1b-d). He also had a left single palmar crease, prominent finger pads, 5th finger clinodactyly, bilateral hallux valgus and clinodactyly of toes 3 to 5 . On neurologic exam he had normal strength and deep tendon reflexes, mildly decreased central tone and a wide based gait.

The proband's father (UDP_4637; II-1, Fig. 1a) had a similar history of developmental delay and impaired speech development. He finished high school with assistance and worked in a fast food restaurant. Formal neurocognitive testing at age 31 years using Wechsler Adult Intelligence Scale, Fourth Edition (WAIS-IV) and Adult Self-Report (ASR) for Ages 18-59 revealed mild intellectual disability with nonverbal reasoning significantly lower than verbal reasoning. On physical exam, his height was $173 \mathrm{~cm}$ (31st centile), and his head circumference was $57 \mathrm{~cm}$ (56th centile). His dysmorphic features included mild plagiocephaly, a high forehead, high anterior hairline, upslanting palpebral fissures, simple ear helices, prominent chin, high arched palate, left single palmar crease, and prominent finger pads (Fig. 1e, f). His neurologic examination was normal.

The proband's paternal grandmother (UDP_4638; I-2, Fig. 1a) had clinical depression and had undergone multiple surgeries for keratoconus. Her height measured $158.4 \mathrm{~cm}$ (23rd centile), and her head circumference was $53.5 \mathrm{~cm}$ (22nd centile). She had a high forehead, bulbous nasal tip, and mild proptosis (Fig. 1g, h). At age 53 years, her neurologic examination was unremarkable. Formal testing by WAIS-IV, ASR and Wechsler Memory Scale Fourth Edition (WMS-IV) revealed a mild intellectual disability as well as verbal and visual memory impairments.

\section{Results of additional investigations}

Normal laboratory investigations for the proband included a complete blood count and blood electrolytes, lipid profile, liver and kidney function tests, and blood levels for ammonia, lactate, thyroid stimulating hormone and gonadotropic steroids. He also had unremarkable plasma amino acid and urine organic acid profiles and a normal skeletal survey and bone age. He tested negative for an FMR1 repeat expansion. Chromosome analysis revealed an apparently balanced translocation, 46,XY, t(14;18)(q22;q21) and chromosomal microarray analysis (GenomeDXv2.0) found no clinically significant copy number variants. The proband's father and paternal grandmother had the same 
chromosome translocation. A brain MRI performed on the proband's father showed no structural or myelination abnormalities.

\section{Methods}

Characterization of the cytogenetically identified translocation and delineation of the potential mechanism of disease was conducted by a series of molecular analyses that included whole genome and transcriptome sequencing followed by validation studies (Additional file 1: Figure S1).

\section{Nucleic acid extraction}

Genomic DNA was extracted from peripheral whole blood using the Gentra Puregene Blood kit (Qiagen, Valencia, CA) per the manufacturer's protocol. Total RNA was extracted from cultured skin fibroblasts using the RNeasy Mini Kit (Qiagen, Valencia, CA) per the manufacturer's protocol. Total RNA from patient and control peripheral whole blood samples was purified using the QuickGene 810 automated extraction machine (Autogen, Holliston, MA) with an on column DNase digestion. The quality and quantity of RNA was verified using an Agilent 2100 Bioanalyzer (Agilent Technologies, Santa Clara, CA) and NanoDrop 8000 (Thermo Scientific, Waltham, MA).

\section{SNP Chip analysis}

The Illumina GenomeStudio ${ }^{\mathrm{TM}}$ software (V2011.1, Illumina, San Diego, CA) was used to define the population frequency of the B allele (PFB) statistics for 662 samples from unrelated Undiagnosed Diseases Program (UDP) individuals. Samples were run on the Illumina Human OmniExpress-12v1_A chip and the resulting PFB file was filtered for mitochondrial and chromosomal 0 SNP data. Post-filtering, GenTrain score (clustering algorithm score), genotype, B Allele Frequency (BAF), and log R Ratio (LRR) for the proband were generated and exported. The proband input file was run against the filtered PFB file using PennCNV [33] with thresholds of 2, 5, or 10 SNPs to generate threshold specific copy number variant (CNV) calls.

All CNV calls were manually inspected and validated for accuracy. Each copy number $(\mathrm{CN})$ call position was entered into the Illumina Genome Viewer (GenomeStudio $^{\mathrm{TM}}$ ) and inspected with BAF and LRR plots for the proband. Call authenticity was verified by comparing normalized intensity of the A and B allele Cartesian coordinates of the proband to rest of population in the dataset. Illumina GenomeStudio ${ }^{\mathrm{TM}}$ Genotyping Module generated normalized intensity values.

\section{Whole-genome sequencing}

Patient blood genomic DNA libraries were prepared and sequenced according to Illumina (Illumina., San Diego, CA) paired-end sequencing service protocols. Illumina's service package consisted of short-insert (308 median fragment length) paired-end reads from one library with 100 bp read length. The library was barcoded and sequenced on 2 flow-cells (3 lanes) of Illumina HiSeq2000 platform and produced $>89$ billion high-quality bases (Additional file 2: Table S1). Preliminary bioinformatics alignment analysis of the whole-genome sequencing data was based on the Illumina pipeline (CASAVA 1.8). CASAVA performed multi-seed and gapped alignments on human reference sequence (NBCI Build 37; hg19). Sequences with more than two mismatches and duplicated sequences corresponding to PCR amplification bias were excluded (Additional file 3: Table S2). This left a total of 3,697,786 SNVs with a heterozygous : homozygous non-reference ratio of 1.5 (Additional file 1: Table S3).

\section{Detection of structural variations from whole-genome se- quence data}

Inter- and intra-chromosomal structural variations (SVs) from the Illumina ELAND alignments were detected with BreakDancer (version 1.1) and an in-house program, BREAKER (Cherukuri PF, et al. unpublished data); SVs were called with stringent criteria (-q 35 -r 2). BreakDancer calls were filtered to include only SV calls in which either plus or minus strand reads were at maximum 60 at both breakpoints and were supported by at least 12 plus or minus strand reads. The maximum cutoff was performed to discard regions with suspiciously high sequencing depth. BreakDancer calls with scores of 99 and higher were included in further analysis. These high confidence SV calls were filtered against (1) DGV high-throughput sequencing variants (UCSC track table), (2) Segmental Duplications (UCSC track table), and (3) HiSeq depth regions (top $5 \%$ UCSC track table). In steps 1, 2 and 3, an SV call was filtered out if at least one of the breakpoints was located within a \pm 500 bp window of a repetitive genomic region (in case of a translocation, a 1001 bp window centered on the breakpoint). These SV candidate calls were visually inspected with IGV and validated. This methodology found 22 putative insertions, deletions and inversion candidates. Of these candidates, 5 were within genes (4 autosomal; $1 \mathrm{X}$-linked), and two interrupted a protein coding sequence: MIER1 and QPCT. Eighty-four percent of the BreakDancer calls were manually assessed as false positives after the systematic filtering. Single short-reads mapped across the candidate inter-chromosomal translocation break-point: chr14:chr18.

\section{Tissue culture}

Skin fibroblasts were obtained from skin biopsies. Both affected fibroblasts and unaffected control fibroblasts were grown in high-glucose DMEM medium with L-glutamine (Life Technologies, Carlsbad, CA) supplemented with $10 \%$ fetal bovine serum and $1 \%$ Antibiotic-Antimycotic (Life Technologies, Carlsbad, CA). Cultured fibroblasts 
were incubated in a humidity-controlled environment at $37^{\circ} \mathrm{C}$, with $95 \% \mathrm{O}_{2}$ and $5 \% \mathrm{CO}_{2}$. The medium was exchanged for fresh medium every 3 days, and the cells were used before passage 10 .

\section{RNA-seq Method}

Poly-A selected RNA-seq libraries were constructed from $1 \mu \mathrm{g}$ mRNA using the Illumina TruSeq RNA Sample Prep Kits, version 2 (Illumina, San Diego, CA). The resulting cDNA was fragmented using a Covaris E210. Library amplification was performed using 8 cycles to minimize the risk of over-amplification. Unique barcode adapters were applied to each library. Libraries were quantitated by qPCR using the KAPA Library Quantification Kit (KAPA Biosystems) and pooled in an equimolar ratio. The pooled libraries were sequenced on a $\mathrm{GA}_{\mathrm{ii}} \mathrm{x}$. At least 40 million 101-base read pairs were generated for each individual library. Data were processed using RTA 1.12.4.2 and CASAVA 1.8.2.

\section{Transcriptome data processing and data analysis}

Transcriptome fastq reads (phred33-scaled) were mapped onto the human genome assembly hg19 using Bowtie 2 in TopHat2 (v.2.0.3) [34, 35]. Pre-computed human reference sequence (NBCI Build 37; hg19) Bowtie2 index files were used as the index files for read mapping. The UCSC known gene splice junction library (GTF file) was used for splice-read mapping; in addition, the fusion-search parameter switch was turned on to enable gene-fusion derived transcript discovery. Transcript assembly, abundance estimates and differential expression analyses were performed using Cufflinks2 (v2.2.1) and Cuffdiff2 (v2.2.1) [35, 36]. Differential gene expression comparisons were run without biological replicates; therefore biological sample gene variance could not be estimated. Differential expression was calculated as fold-changes in gene expression (measured as fragments per kilobase mapped (FPKM)). Pseudo-count of FPKM 1 was added to all FPKM values to minimize inflation of differential gene expression log-likelihood ratios (base 10). Local neighborhood gene-differential analysis was performed at chromosomal breakpoint junctions, using Pearson correlation coefficient to detect anti-correlated gene expression signature deviation from expectation.

\section{Analysis of gene expression on chromosomes 14 and 18} The Pearson correlation coefficient of gene expression on chromosomes 14 and 18 was calculated using all-possible pairs $\left(N^{2}\right)$ resulting from a window of 3 genes. The methodology is described in the Additional file 1.

\section{PCR amplification}

Genomic DNA sequences of interest were amplified by polymerase chain reaction using the listed primers
(Additional file 1: Table S4), genomic DNA and Qiagen HotStar Plus Taq polymerase under conditions: $95{ }^{\circ} \mathrm{C} \times 5$ min denaturation followed by 40 cycles of $95{ }^{\circ} \mathrm{C} \times 30 \mathrm{~s}, 55^{\circ} \mathrm{C} \times 30 \mathrm{~s}, 72{ }^{\circ} \mathrm{C} \times 30 \mathrm{~s}$.

\section{Sanger sequencing}

Residual primers and nucleotides were removed by incubation with ExoSAP-IT (USB, Cleveland, $\mathrm{OH}$ ). The amplicons were sequenced by Macrogen (Rockville, MD) using BigDye terminator chemistry and compared to the human reference sequence (NCBI 37/hg19) using Sequencher (GeneCodes, Ann Arbor, MI).

\section{Reverse transcription polymerase chain reaction and quantitative real-time polymerase chain reaction}

For cultured fibroblasts, complementary DNA (cDNA) synthesis was performed on $2 \mu \mathrm{g}$ of total RNA using the OmniScript RT Synthesis kit (Qiagen, Valencia, CA) and Oligo $\mathrm{dT}_{23}$ Anchored Primers (Sigma, St. Louis, MO). The cDNA sequence was verified by $\mathrm{PCR}$ analysis using the listed primers (Additional file 1: Table S5), HotStar Plus Taq polymerase (Qiagen, Valencia, CA) and $100 \mathrm{ng}$ of cDNA under conditions: $95^{\circ} \mathrm{C} \times 5 \mathrm{~min}$ denaturation followed by 40 cycles of $95^{\circ} \mathrm{C} \times 30 \mathrm{~s}, 60^{\circ} \mathrm{C} \times 30 \mathrm{~s}, 72^{\circ} \mathrm{C} \times 30 \mathrm{~s}$.

For peripheral blood, cDNA synthesis was performed on $40 \mathrm{ng}$ of total RNA using the SensiScript RT kit (Qiagen, Valencia, CA) and Oligo $\mathrm{dT}_{23}$ Anchored Primers (Sigma, St. Louis, MO). The cDNA sequence was verified by PCR analysis using the listed primers (Additional file 1: Table S5), HotStar Plus Taq polymerase (Qiagen, Valencia, CA) and $80 \mathrm{ng}$ of cDNA under conditions: $95{ }^{\circ} \mathrm{C} \times 5 \mathrm{~min}$ denaturation followed by 40 cycles of $95^{\circ} \mathrm{C} \times 30 \mathrm{~s}, 60^{\circ} \mathrm{C} \times$ $30 \mathrm{~s}, 72^{\circ} \mathrm{C} \times 30 \mathrm{~s}$.

Quantitative real-time PCR was performed on $80 \mathrm{ng}$ of cDNA, the listed primers (Additional file 1: Table S5) and the QuantiFast SYBR Green PCR Kit (Qiagen, Valencia, CA), and analyzed with the ABI 7500 Fast Real-Time PCR System (Life Technologies, Carlsbad, CA). Target amplification was normalized to that of GAPDH and shown as expression relative to control.

\section{Digital droplet PCR}

Digital droplet PCR analysis was performed on $50 \mathrm{ng}$ of cDNA derived from patient and control fibroblast RNA using TaqMan Genotyping Mastermix (Life Technologies, Carlsbad, CA) and TaqMan Gene Expression Assay for rs1261084 (Life Technologies, Carlsbad, CA) under conditions: $95^{\circ} \mathrm{C} \mathrm{x} 10 \mathrm{~min}$ denaturation followed by 40 cycles of $95{ }^{\circ} \mathrm{C} \times 15 \mathrm{~s}, 60{ }^{\circ} \mathrm{C} \times 60 \mathrm{~s}$ both with a ramp speed of $0.5^{\circ} \mathrm{C}$ per second. The amplified products (4 million droplets per sample) were read on the RainDrop Digital PCR System (RainDance Technologies, Billerica, MA) and analyzed using the Raindrop Analyst software. Results were normalized to control fibroblasts. 


\section{nCounter gene expression assay}

The nCounter Gene expression assay was performed on $100 \mathrm{ng}$ of total RNA derived from human blood peripheral leukocytes or cultured fibroblasts from the patient, PTHS controls, and unaffected controls (Clontech, Mountain View, CA). The RNA samples were hybridized at $65{ }^{\circ} \mathrm{C}$ for a minimum of $12 \mathrm{~h}$ to the Capture and Reporter probesets (nanoString Technologies, Seattle, WA) that were designed to include the listed TCF4 transcript variants (Additional file 1: Table S6). These complexes were immobilized onto a cartridge and analyzed by the nCounter Digital Analyzer (nanoString Technologies, Seattle, WA). Geometric means were used to calculate the normalization factor and data were normalized to GAPDH expression. The results were analyzed, calculated relative to control gene expression in blood derived samples, and reported as the $\log _{2}$ ratio relative to control TCF4 transcript levels.

\section{Results}

\section{TCF4 is disrupted by a complex chromosomal} translocation that segregates with ID in three generations To identify genes disrupted by the apparently balanced translocation between chromosomes 14 and 18, we generated a 308 bp-insert Illumina whole-genome sequencing library for whole genome sequencing. The 100 bp pairedend sequencing of whole blood DNA generated 1,094, 407,124 individual reads with 452 million high-quality pairs. Analysis of aligned pairs identified a cluster of reads with ends mapping to chromosome 14 and 18. From this analysis, 30 read pairs with high-quality mapping localized to a single origin in the first intron of PLEKHG3 (NM _015549.1) on chromosome 14 (chr14: 65,191,597-65,191, 620) (Fig. 2a), and 29 bp (chr14: 65,191,595-65,191,623) were deleted at the breakpoint (Additional file 1: Figure S1).

On chromosome 18 (18q21.2), the cluster-signal split nearly in half (14 read-pairs, and 16 read-pairs) and mapped to two distinct locations $0.98 \mathrm{Mb}$ apart (Fig. 2a). Further analysis of reads from this region of chromosome 18 suggested an inversion of $18 \mathrm{q} 21.2$. This inversion (0.98 Mb, chr18: 52,256,629- 53,200,017) encompassed $R A B 27 B, C C D C 68$, and interrupted TCF4 and DYNAP (Fig. 2b, Additional file 1: Figure S2). The centromeric breakpoint deleted $38.9 \mathrm{~Kb}$ (chr18: 52,217,704-52,256,628) including the promoter and first exon of DYNAP transcript NM_173629. The telomeric breakpoint deleted 19.4 Kb (chr18: 53,200,018-53,219,411) within TCF4; this did not delete any defined promoters or exons for transcripts of TCF4. We confirmed the inversion breakpoints (chr18: $53,200,017)$ by PCR amplification and Sanger sequencing (Fig. 2b, Additional file 1: Figure S2).

On one derivative chromosome, the portion of chromosome 14 centromeric to the PLEKHG3 intron 1 breakpoint (chr14: 65,191,597) was joined to the breakpoint of the inverted terminal portion of TCF4 (chr18: 53,200,017) and the telomeric portion of 18q (Fig. 3a, Additional file 1: Figure S2). On the second derivative chromosome, the portion of chromosome 18 centromeric to the breakpoint within DYNAP (chr18: 52,217,703) was joined to the portion of $14 \mathrm{q}$ telomeric to the PLEKHG3 intron 1 breakpoint (chr14: 65,191,620) (Fig. 3b, Additional file 1: Figure S2). These findings give a revised karyotype of 46,XY,del(14) (q23.3q23.3)del(18)(q21.2q21.2)del(18)(q21.2q21.2)inv(18) (q21.2q21.2)t(14;18)(q23.3;q21.2)(14pter 14 q23.3::18q21.2 ${ }^{\circledR} 18 q 21.2:: 18 q 21.1^{\circledR} 18 q$ ter;18pter ${ }^{\oplus}$ 18q21.2::14q23.3 ${ }^{\circledR} 14 q$ ter.

\section{The translocation does not disrupt global gene- expression patterns on the derivative chromosomes (der14 and der18)}

Given the observation that patients in our study did not share the distinctive features of Pitt Hopkins syndrome (Table 1), the syndromic form of ID associated with heterozygous TCF4 mutations, and the potential for translocated chromosomal segments to have altered gene expression [37], we used quantitative RNA sequencing to test for gene expression changes on chromosomes 14 and 18 (see Methods). Using RNA extracted from cultured skin fibroblasts of individual II-1 and matched controls, we generated libraries and performed $101 \mathrm{bp}$ paired-end transcriptome sequencing. This generated 114,477,006 (II-1) and 112,237,295 (control) high-quality reads for processing and evaluation using standard bioinformatics methodologies [34, 35]. Since chromosomal rearrangements can disrupt the spatial connection between a gene and its regulatory elements [38], we asked whether there were detectable patterns of gene-misregulation on the derivative chromosomes by computing the cross-correlation of all genes (Pearson correlation coefficient) along chromosomes 14 (755 genes) and 18 (324 genes). We generated the Pearson correlation coefficient matrix $\left(M_{i, j}\right)$ for all pairs of genes and evaluated the topological overlap along the diagonal for signatures of anti-correlation along the entire length of chromosomes 18 and 14 (Additional file 1: Figure S3A, B). Data from experiments did not reject the null hypothesis, suggesting that any observed alterations in gene expression were random. Nonetheless, to characterize further the local expression ordering, we performed windowmodularity gene-expression analysis by comparing expression between patient and control fibroblasts $[39,40]$. These analyses also did not reveal statistically significant differences in gene-expression patterns. We concluded, therefore, that gene expression changes across large regions of chromosomes 14 and 18 were either unlikely to be the cause of this patient's phenotype or were undetectable in cultured fibroblasts.

Given the lack of regional gene expression changes on chromosomes 14 and 18, we focused on gene expression patterns at the chromosomal rearrangement breakpoints to look for evidence of proximal-regulatory effects [38]. 
a

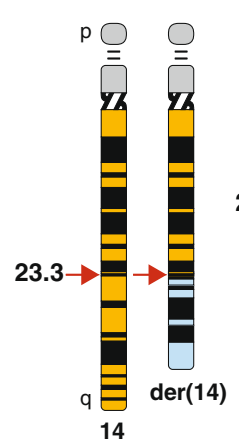

b

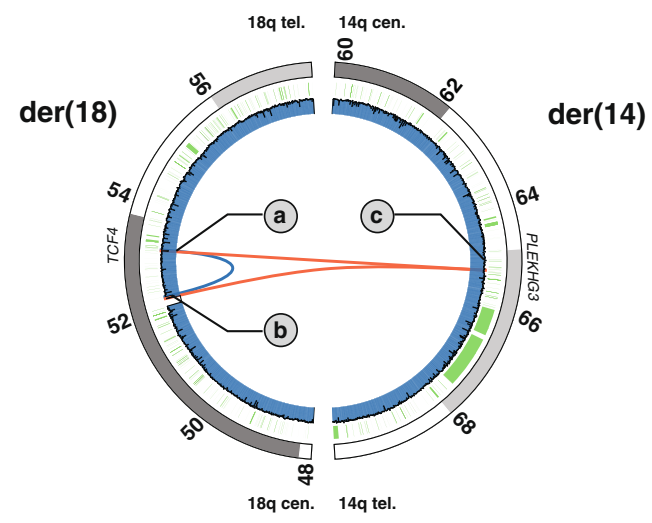

C

(c)

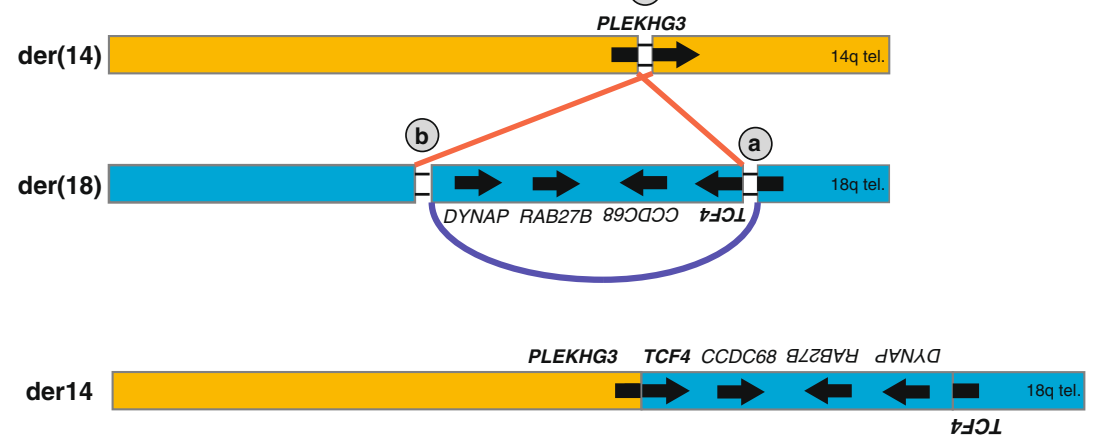

der18

Fig. 2 Delineation of a balanced translocation (t(14;18)) disrupting transcription factor 4 (TCF4) using whole genome sequencing of patient DNA. (a) Ideogram depicting the patient's apparently balanced translocation $t(14,18)(q 23.2 ; q 21.2)$ and normal karyotype $(46, X Y)$. The ideogram of chromosome 18 is shaded in light blue color. (b) Inter-chromosome (red; chr18-chr14) and intra-chromosome (blue; chr18-chr18) connections identified by whole-genome sequence analysis. Intra-chromosomal inversion (943,387 bases) on chr18 encompasses RAB27B, and CCDC68 and interrupted DYNAP and TCF4. The inversion junctions are flanked by heterozygous deletions within TCF4 (19,394 bases (a)) and include the promoter and first exon of DYNAP transcript NM_173629 (38,926 bases (b)). Inter-chromosome connection on chr14 disrupts PLEKHG3 resulting in a 29 bp heterozygous deletion (c). Blue and orange arrows indicate genes on the positive and negative strand respectively. Dark blue and green wiggles indicate read depth via whole-genome sequencing, and segmental duplications (hg19 UCSC Human genome browser) respectively. (c) Schematic representation mechanism of the three ds-DNA breaks and genomic reorganization steps that led to the translocation event between chromosome 14 and 18. The three main steps were: (1) a $0.94 \mathrm{Mb}$ inversion (blue arch, breakpoints a and b) on chromosome 18, followed by (2) ligation of the centromeric portion of chromosome 14 (red line, breakpoints $\mathbf{c}$ and $\mathbf{a}$ ) with the telomeric $\mathrm{q}$ arm of chromosome 18 to yield der (14), and (3) ligation of the centromeric portion of chromosome 18 (red line, breakpoints $\mathbf{c}$ and $\mathbf{b}$ ) ligation with the telomeric $q$ arm of chromosome 14 to yield der (18). The schematic representation of chromosomes is not to scale. The der (14) chromosome harbors a gene fusion of PLEKHG3 (5' untranslated region) and TCF4 (coding exons) as well as interrupted TCF4 transcript variants. The der (18) chromosome harbors a disrupted copy of PLEKHG3; the coding potential of the gene remains intact although the promoter and first non-coding exon are removed by the translocation

We tested 14 genes around each balanced translocation breakpoint (Table 2). Of the genes tested on chr14, PLEKHG 3 was unaltered and HSPA2, $164 \mathrm{~kb}$ upstream of PLEKHG3, was marginally down-regulated at 53.2 fragments per kilobase of exon per million fragments mapped (FPKM) vs. 120.3 FPKM for the control ( $P$ value $\left.<5 \times 10^{-05}\right)$. Of the genes tested on chr18, DNYAP was marginally up-regulated at 2.6 FPKM vs. 0 FPKM $\left(P\right.$-value $\left.<5 \times 10^{-05}\right)$ and TCF4, CCDC68, and RAB27B had reduced expression. Total TCF4 expression was 70$80 \%$ of the unaffected control. This level of total TCF4 mRNA was confirmed by qRT-PCR (Fig. 4a-b).

\section{Other genomic variants do not explain the phenotype}

These expression results suggested that a mutation other than chromosomal translocation might be responsible for the observed phenotype. To identify potential pathogenic single-nucleotide variants (SNVs), small insertions, 


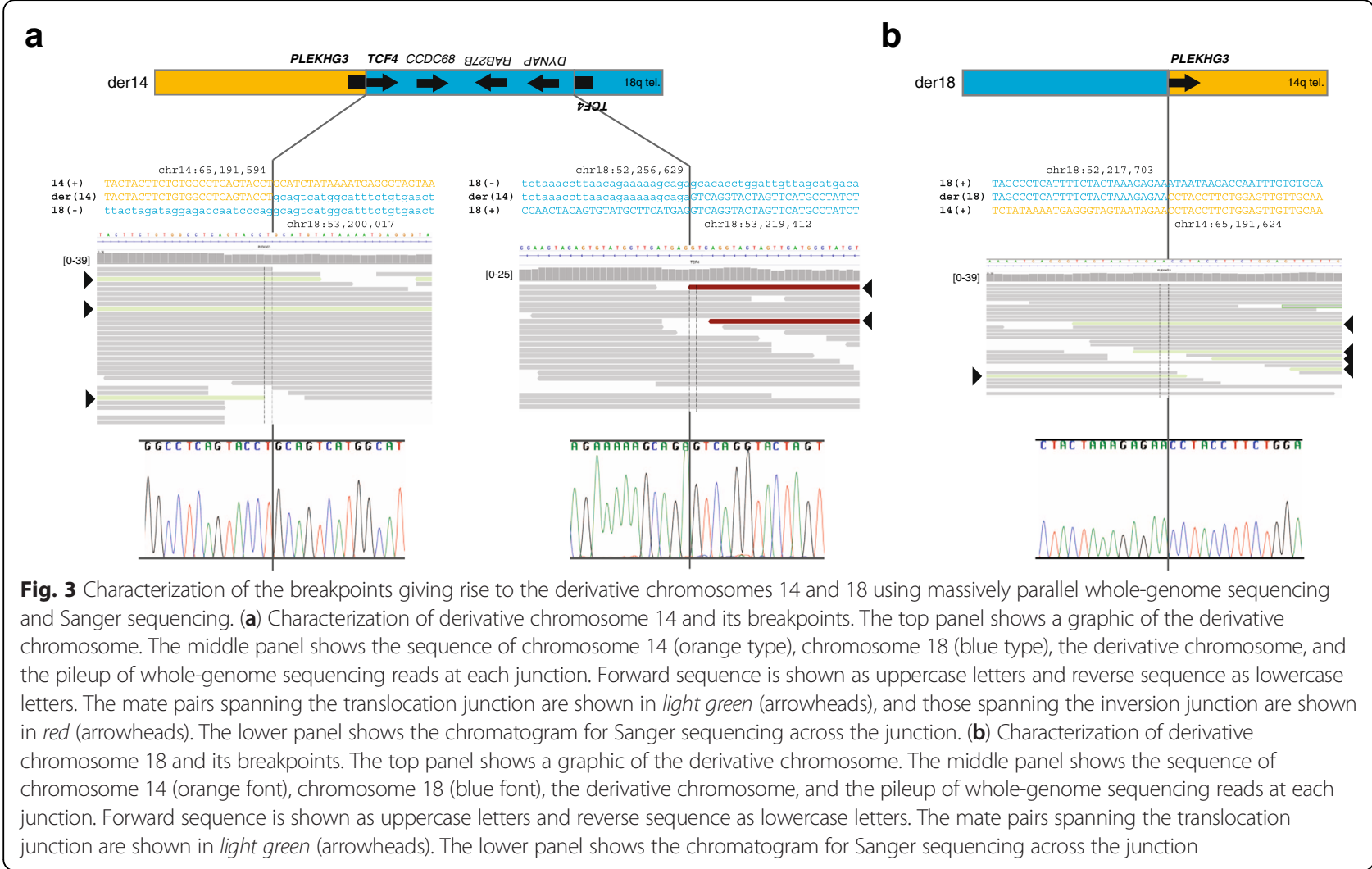

deletions, and genomic copy number aberrations, we integrated data from the short-insert library wholegenome sequencing and SNP chip analysis. Concordance of array- and sequence-based SNP calling exceeded 99.2\%. Bases within genes and their corresponding exons exceeded $98 \%$ coverage with each base sequenced $>10$ fold on average. We identified a total of 3.6 million single nucleotide differences (>Q20; heterozygote/homozygote ratio $=1.6 ;$ transition $/$ transversion ratio $=2.05$ ) between the proband genome and the human reference sequence (NCBI build 37; hg19). Most SNVs (>94 \%) were common variants in the general population, and $1.6 \%$ of the SNVs localized to exonic regions. Of the exonic SNVs, 461 of these were unreported or had a frequency of $<0.1 \%$ in dbSNP. We ranked these 461 variants by various pathogenicity prediction software including CDPred [41] and PolyPhen2 [42]. None of these candidate variants showed potential to cause ID (data not shown). In the absence of another likely strong candidate variant to explain the phenotype of the patients, we concluded that the disruptions of TCF4 or PLEKHG3 remained the most likely causes.

Analysis of the sequence data from the disrupted genes found that PLEKHG3, DYNAP, and TCF4 had no missense changes. TCF4 had two heterozygous synonymous polymorphisms, rs1261084 and rs1261085.

\section{Altered expression of TCF4 is the most likely cause of milder form of ID}

A recent study reported a patient with a chromosomal translocation disrupting TCF4 and a phenotype milder than PTHS [43]. Because this report attributed the mild phenotype to expression of a TCF4 fusion transcript, we analyzed cultured skin fibroblasts for expression from the TCF4 locus. The derivative chromosome fusing PLEKHG3 intron 1 (NM_001308147.1; chr14: 65,191,597) to TCF4 intron 3 (NM_001083962.1; chr18: 53,200,017) is compatible with generation of a fusion transcript initiating at the PLEKHG3 transcriptional start site and extending from exon 4 through the remaining exons of TCF4 (NM_001083962.1, TCF4-B+); this fusion transcript has potential to encode a protein initiating in exon 4 of TCF4 (Additional file 1: Figure S4). To test for such a fusion transcript, we mapped the mate-pairs from the RNASeq data, described above, against human reference sequence (NCBI 37, hg19) with TopHat. Gene expression was evaluated with Cufflinks and mate-pairs were categorized as (a) mapping to the same gene or (b) mapping to different genes on different chromosomes. This detected a gene-fusion between exon 1 of PLEKHG3 (chr14: 65,171,193-65,171,422) and exon 4 of TCF4 (NM_001083962.1; chr18: 53,131,307-53,131,368); 4 paired-end reads and 11 single reads spanned the junction (TopHat fusion and BLAT alignment of unaligned reads) 
Table 1 Comparison of our patients' features to individuals reported with TCF4 mutations

\begin{tabular}{|c|c|c|c|c|c|}
\hline \multirow[t]{2}{*}{ Feature } & \multicolumn{3}{|c|}{$\begin{array}{l}\text { Summary of reported patients } \\
{[27-29,31,43-45,49-61]}\end{array}$} & \multicolumn{2}{|c|}{ Our patients } \\
\hline & $\begin{array}{l}\text { No. reported } \\
\text { with feature }\end{array}$ & $\begin{array}{l}\text { Total reported } \\
(n=121)\end{array}$ & $\%$ & $\begin{array}{l}\text { No. with } \\
\text { feature }\end{array}$ & $\begin{array}{l}\text { Total } \\
(n=3)\end{array}$ \\
\hline $\begin{array}{l}\text { Pitt Hopkins facial } \\
\text { gestalt }\end{array}$ & 109 & 114 & 96 & 0 & 3 \\
\hline Deep set eyes & 85 & 103 & 83 & & \\
\hline $\begin{array}{l}\text { Protrusion of } \\
\text { mid/lower face }\end{array}$ & 96 & 105 & 91 & & \\
\hline $\begin{array}{l}\text { Marked nasal } \\
\text { root }\end{array}$ & 90 & 105 & 86 & & \\
\hline $\begin{array}{l}\text { Broad/beaked } \\
\text { bridge }\end{array}$ & 99 & 106 & 93 & & \\
\hline Flared nostrils & 90 & 106 & 85 & & \\
\hline Large mouth & 101 & 109 & 93 & & \\
\hline Tented upper lip & 102 & 107 & 95 & & \\
\hline Everted lower lip & 94 & 107 & 88 & & \\
\hline \multicolumn{6}{|l|}{ Hands } \\
\hline Long fingers & 26 & 46 & 57 & 1 & 3 \\
\hline $\begin{array}{l}\text { Single palmar } \\
\text { crease }\end{array}$ & 52 & 88 & 59 & 3 & 3 \\
\hline $\begin{array}{l}\text { Prominent finger } \\
\text { pads }\end{array}$ & 31 & 69 & 45 & 2 & 3 \\
\hline $\begin{array}{l}\text { Additional } \\
\text { palmar creases }\end{array}$ & 5 & 32 & 16 & 0 & 3 \\
\hline Thumb ankylosis & 10 & 68 & 15 & 0 & 3 \\
\hline \multicolumn{6}{|l|}{ Feet } \\
\hline Pes planus & 15 & 25 & 60 & 1 & 1 \\
\hline Pes cavus & 4 & 22 & 18 & 0 & 1 \\
\hline Overriding toes & 15 & 38 & 39 & 0 & 1 \\
\hline Talipes equivarus2 & 6 & 24 & 25 & 0 & 3 \\
\hline \multicolumn{6}{|l|}{ Genitalia } \\
\hline Abnormal & 21 & 57 & 37 & 0 & 1 \\
\hline Cryptorchidism & 14 & 42 & 33 & 0 & 1 \\
\hline \multicolumn{6}{|l|}{ Spine } \\
\hline Scoliosis & 15 & 79 & 19 & 0 & 3 \\
\hline $\begin{array}{l}\text { Ophthalmological } \\
\text { findings }\end{array}$ & 73 & 104 & 70 & & \\
\hline Strabismus & 65 & 113 & 58 & 0 & 3 \\
\hline Myopia & 43 & 86 & 50 & 2 & 3 \\
\hline $\begin{array}{l}\text { Gastrointestinal } \\
\text { findings }\end{array}$ & 17 & 26 & 65 & 0 & 3 \\
\hline Constipation & 66 & 101 & 65 & & \\
\hline GER & 8 & 44 & 18 & & \\
\hline $\begin{array}{l}\text { Hirschsprung } \\
\text { disease }\end{array}$ & 1 & 74 & 1 & & \\
\hline
\end{tabular}

Table 1 Comparison of our patients' features to individuals reported with TCF4 mutations (Continued)

\begin{tabular}{|c|c|c|c|c|c|}
\hline \multicolumn{3}{|l|}{ Growth findings } & & \multirow[t]{2}{*}{0} & \multirow[t]{6}{*}{3} \\
\hline Height $<2$ SD & 19 & 80 & 24 & & \\
\hline Weight $<2$ SD & 9 & 58 & 16 & & \\
\hline $\mathrm{OFC}<-2 \mathrm{SD}$ & 17 & 65 & 26 & & \\
\hline OFC on -2 SD & 13 & 49 & 27 & & \\
\hline Microcephaly & 56 & 113 & 50 & & \\
\hline \multicolumn{6}{|l|}{$\begin{array}{l}\text { Developmental } \\
\text { findings }\end{array}$} \\
\hline Severe ID or DD & 117 & 119 & 98 & 0 & 3 \\
\hline Hypotonia & 69 & 80 & 86 & & \\
\hline Delayed walking & 81 & 83 & 98 & 0 & 1 \\
\hline $\begin{array}{l}\text { Walking } \\
\text { achieved }\end{array}$ & 53 & 65 & 82 & 3 & 3 \\
\hline Ataxic gait & 44 & 68 & 65 & 0 & 3 \\
\hline $\begin{array}{l}\text { Absent language } \\
\text { or }<5 \text { words }\end{array}$ & 105 & 108 & 97 & 0 & 3 \\
\hline $\begin{array}{l}\text { Movement } \\
\text { anomalies }\end{array}$ & 81 & 106 & 76 & 0 & 3 \\
\hline Arm flapping & 28 & 47 & 60 & & \\
\hline $\begin{array}{l}\text { Hand biting/ } \\
\text { nibbling }\end{array}$ & 17 & 38 & 45 & & \\
\hline $\begin{array}{l}\text { Repetitive finger } \\
\text { movements }\end{array}$ & 12 & 25 & 48 & & \\
\hline $\begin{array}{l}\text { Repetitive wrist } \\
\text { movements }\end{array}$ & 10 & 21 & 48 & & \\
\hline Hand wringing & 11 & 24 & 46 & & \\
\hline $\begin{array}{l}\text { Head } \\
\text { stereotypies }\end{array}$ & 11 & 26 & 42 & & \\
\hline $\begin{array}{l}\text { Median line } \\
\text { stereotypies }\end{array}$ & 14 & 35 & 40 & & \\
\hline Behavioral findings & & & & 0 & 3 \\
\hline Smiling/happy & 86 & 99 & 87 & & \\
\hline Harm to self & 21 & 59 & 36 & & \\
\hline Harm to others & 12 & 61 & 20 & & \\
\hline $\begin{array}{l}\text { Sleep } \\
\text { disturbances }\end{array}$ & 15 & 63 & 24 & & \\
\hline Anxiety/agitation & 29 & 49 & 59 & & \\
\hline $\begin{array}{l}\text { Unmotivated } \\
\text { laughing }\end{array}$ & 19 & 30 & 63 & & \\
\hline $\begin{array}{l}\text { Breathing } \\
\text { anomalies }\end{array}$ & 72 & 116 & 62 & 0 & 3 \\
\hline Hyperventilation & 54 & 99 & 55 & & \\
\hline Apnoea & 35 & 65 & 54 & & \\
\hline Cyanosis & 11 & 36 & 31 & & \\
\hline $\begin{array}{l}\text { Loss of } \\
\text { consciousness }\end{array}$ & 5 & 34 & 15 & & \\
\hline Chronic hypoxia & 3 & 31 & 10 & & \\
\hline Finger clubbing & 3 & 33 & 9 & & \\
\hline
\end{tabular}


Table 1 Comparison of our patients' features to individuals reported with TCF4 mutations (Continued)

\begin{tabular}{|c|c|c|c|c|c|}
\hline$\overline{\text { Seizures (history) }}$ & 44 & 113 & 39 & 0 & 3 \\
\hline Abnormal head MRI & 59 & 95 & 62 & 0 & 1 \\
\hline $\begin{array}{l}\text { Hypoplasia or } \\
\text { agenesis of cc }\end{array}$ & 36 & 83 & 43 & & \\
\hline Ventriculomegaly & 24 & 71 & 34 & & \\
\hline $\begin{array}{l}\text { Abnormal } \\
\text { myelination or } \\
\text { reduced white } \\
\text { matter }\end{array}$ & 5 & 29 & 17 & & \\
\hline Cortical atrophy & 6 & 37 & 16 & & \\
\hline $\begin{array}{l}\text { Minor posterior } \\
\text { fossa anomalies }\end{array}$ & 6 & 22 & 27 & & \\
\hline $\begin{array}{l}\text { Dentate nuclei } \\
\text { hyperintensity }\end{array}$ & 4 & 25 & 16 & & \\
\hline $\begin{array}{l}\text { Small } \\
\text { hippocampi }\end{array}$ & 11 & 41 & 27 & & \\
\hline $\begin{array}{l}\text { Temporal lobe } \\
\text { hyperintensity }\end{array}$ & 13 & 51 & 25 & & \\
\hline $\begin{array}{l}\text { Frontal lobe } \\
\text { hypoplasia }\end{array}$ & 3 & 30 & 10 & & \\
\hline $\begin{array}{l}\text { Large caudate } \\
\text { nuclei }\end{array}$ & 4 & 45 & 9 & & \\
\hline $\begin{array}{l}\text { Normal birth } \\
\text { parameters }\end{array}$ & 36 & 41 & 88 & 1 & 1 \\
\hline
\end{tabular}

(data not shown). This analysis did not detect a fusion transcript between TCF4 and DYNAP. RT-PCR of skin fibroblast total RNA and Sanger sequencing of the products confirmed the PLEKHG3-TCF4 fusion transcript (Fig. 4c) and the absence of a TCF4-DYNAP fusion transcript (data not shown). Contrary to the hypothesis that the PLEKHG3-TCF4 fusion transcript contributed substantial TCF4 transcripts, the RNASeq analysis detected few fusion mRNAs.

To determine if the paucity of fusion transcripts was an artifact of cell culture, we tested cDNA derived from peripheral blood by qRT-PCR. Quantitation of the 12 RefSeq TCF4 transcripts (Fig. 4d) showed that total TCF4 mRNA levels in the blood of the patients were 14-33 fold higher than for unaffected controls (Fig. 4e) and that the fusion transcripts from the derivative chromosome constituted only 2-3\% of the total TCF4 expression for all transcripts (Fig. 4f). Focusing on transcripts interrupted by the translocation (NM_001243226.1, NM_001243227.1, NM_001243228.1, NM_001243230.1, NM_003199.2, NM_001083962.1) (Fig. 4d), qRT-PCR of cDNA derived from blood showed that mRNA levels for these transcript variants, inclusive of the PLEKHG3-TCF4 fusion transcript, were expressed at only $10-20 \%$ of the level of the control (Fig. 4g). We concluded therefore that expression of a fusion transcript did not rescue overall TCF4 expression [43].
Because TCF4 has promoters distal to the translocation breakpoint, we hypothesize that the rescue of TCF4 expression and that the moderation of the patient phenotype arises from increased expression of these shorter transcripts. To test this, we compared RNA extracted from blood of II-1 (UDP_4637) and III-3 (UDP_4765), PTHS controls and unaffected controls using an nCounter Gene expression assay with probes distinguishing many TCF4 transcripts (Additional file 1: Table S6). Compared to the unaffected controls, the patient blood RNA had increased levels of total TCF4 mRNA and of transcripts (NM_001243231.1, NM_001243233.1, NM_001243232.1, NM_001243235.1, NM_001243234.1, NM_001243236.1) initiating downstream of the translocation breakpoint, whereas it had decreased or unchanged levels of transcripts (NM_001243226.1, NM_001243227.1, NM_001243228.1, NM_001243230.1, NM_003199.2, NM_001083962.1) initiating upstream of the translocation (Fig. 4h). Compared to the unaffected controls and as predicted for nonsense mediated mRNA decay, the two individuals with PTHS had decreased levels of mRNA for most TCF4 transcripts (Fig. 4e, h).

To determine whether the upregulated transcripts arose from the translocated chromosome, we performed digital droplet PCR for expression of rs1261085, a SNP within the 3' UTR of all TCF4 transcripts and for which the propositus' father is heterozygous. Using cDNA derived from blood of II-1, we found that half of the TCF4 mRNA was derived from the derivative chromosome and half from the wildtype allele (data not shown).

\section{Discussion}

We demonstrate that a chromosomal translocation interrupting proximal TCF4 segregates with mild ID and defines a genomic interval critical for this phenotype versus PTHS. Additionally, we find that although such translocations can produce fusion transcripts, increased transcription from TCF4 promoters distal to the breakpoint likely ameliorates the phenotype, i.e. prevents the congenital anomalies and neurologic co-morbidity typical of PTHS.

Despite the disruption of TCF4, the individuals reported herein did not meet the diagnostic criteria for PTHS (Table 1) [32, 44]. Using two PTHS clinical scoring systems, the affected individuals considered herein had a clinical score of only 1 on the system of Marangi et al., in which a minimum score of 10 is an indication for TCF4 mutation analysis [44], and they had 0 out of 20 criteria on the system of Whalen et al. in which a score of $>15$ is an indication for TCF4 mutation screening [32].

To understand better the genotype-phenotype correlation, we analyzed the transcripts affected by translocations causing PTHS versus mild ID [43, 45, 46]. Using the TCF4 structure defined by Sepp et al. [30], the translocation of our patient and the patient reported by Schluth- 
Table 2 Expression of genes near the chromosome 14 and 18 breakpoints

\begin{tabular}{|c|c|c|c|c|c|c|c|}
\hline \multicolumn{8}{|l|}{ Chromosome 18} \\
\hline Gene & Chromosome & UDP4637 FPKM & Control FPKM & log (UDP/Control) & $p$-value & q-value & Significant \\
\hline MBD2 & chr18 & 10.0 & 9.0 & -0.15 & 0.250 & 0.39 & no \\
\hline SNORA37 & chr18 & 0.0 & 0.0 & 0.00 & 1.000 & 1.00 & no \\
\hline POLI & chr18 & 3.7 & 2.7 & -0.47 & 0.001 & 0.00 & yes $^{a}$ \\
\hline STARD6 & chr18 & 0.0 & 0.0 & 0.00 & 1.000 & 1.00 & no \\
\hline C18orf54 & chr18 & 3.0 & 1.4 & -1.09 & 0.000 & 0.00 & yes $^{\text {a }}$ \\
\hline DYNAP & chr18 & 2.6 & 0.0 & N/A & 0.000 & 0.00 & yes $^{a}$ \\
\hline RAB27B & chr18 & 0.6 & 1.7 & 1.52 & 0.000 & 0.00 & yes $^{a}$ \\
\hline CCDC68 & chr18 & 0.3 & 1.1 & 2.02 & 0.000 & 0.00 & yes $^{\text {a }}$ \\
\hline TCF4 & chr18 & 17.6 & 21.5 & 0.29 & 0.026 & 0.06 & no \\
\hline LOC100505474 & chr18 & 0.0 & 0.0 & 0.00 & 1.000 & 1.00 & no \\
\hline TXNL1 & chr18 & 22.5 & 25.7 & 0.19 & 0.155 & 0.27 & no \\
\hline WDR7 & chr18 & 6.7 & 6.4 & -0.08 & 0.563 & 0.70 & no \\
\hline BOD1P & chr18 & 0.0 & 0.0 & inf & 1.000 & 1.00 & no \\
\hline \multicolumn{8}{|l|}{ Chromosome 14} \\
\hline Gene & Chromosome & $\begin{array}{l}\text { UDP4637 } \\
\text { FPKM }\end{array}$ & $\begin{array}{l}\text { Control } \\
\text { FPKM }\end{array}$ & $\begin{array}{l}\log \\
\text { (UDP/Control) }\end{array}$ & $p$-value & q-value & Significant \\
\hline TEX21P & chr14 & 0.1 & 0.1 & -0.04 & 1.00 & 1.00 & no \\
\hline MTHFD1 & chr14 & 32.0 & 29.4 & -0.12 & 0.36 & 0.51 & no \\
\hline AKAP5 & chr14 & 0.1 & 0.5 & 2.15 & 0.00 & 0.00 & yes $^{a}$ \\
\hline ZBTB25 & chr14 & 2.4 & 2.5 & 0.08 & 0.66 & 0.78 & no \\
\hline ZBTB1 & chr14 & 13.2 & 14.6 & 0.15 & 0.28 & 0.42 & no \\
\hline HSPA2 & chr14 & 53.3 & 120.4 & 1.18 & 0.00 & 0.00 & yes \\
\hline PPP1R36 & chr14 & 0.3 & 0.3 & 0.16 & 0.71 & 0.81 & no \\
\hline PLEKHG3 & chr14 & 2.5 & 3.2 & 0.35 & 0.02 & 0.05 & yes $^{a}$ \\
\hline SPTB & chr14 & 0.0 & 0.1 & 0.74 & 1.00 & 1.00 & no \\
\hline CHURC1,CHURC1-FNTB,FNTB & chr14 & 20.3 & 20.4 & 0.01 & 0.97 & 0.98 & no \\
\hline GPX2 & chr14 & 0.0 & 0.0 & inf & 1.00 & 1.00 & no \\
\hline LOC100506321 & chr14 & 0.0 & 0.1 & 1.83 & 1.00 & 1.00 & no \\
\hline MAX & chr14 & 23.2 & 18.8 & -0.31 & 0.26 & 0.40 & no \\
\hline MIR4706 & chr14 & 0.0 & 0.0 & 0.00 & 1.00 & 1.00 & no \\
\hline RAB15 & chr14 & 3.4 & 2.3 & -0.54 & 0.23 & 0.37 & no \\
\hline
\end{tabular}

${ }^{a}$ FPKM value too low to interpret as significant (as evaluated by cufflinks)

Bolard et al. suggest that disruption of all transcripts originating at and proximal to the exon 8 promoters is sufficient to cause PTHS [46], but only disruption of transcripts originating proximal to the exon 8 promoters associates with mild ID. In other words, the minimal set of intact TCF4 transcripts for mild ID are NM_001243231.1, NM_ 001243233.1, NM_001243232.1, NM_001243235.1, NM_ 001243234.1, and NM_001243236.1. In contrast, if transcripts NM_001243231.1, NM_001243233.1 and NM_00124 3232.1 are disrupted along with transcripts NM_00124 3226.1, NM_001243227.1, NM_001243228.1, NM_001243 230.1, NM_003199.2 and NM_001083962.1, the phenotype is PTHS [44, 46]. Affirming this genotype-phenotype correlation, PTHS-associated missense, nonsense, splice site, frame-shift, and deletion mutations minimally alter the transcripts disrupted by the PTHS-associated translocations [30].

Transcripts originating at and proximal to the exon 8 promoters contain a nuclear localization signal (NLS), transcription activation domain (AD) 2 and the basic helixloop-helix domain, whereas transcripts initiating at the exon 10 promoters do not contain an NLS. Transcripts containing the NLS encode products predominantly localized to the nucleus, whereas those products without an NLS are distributed between the nucleus and cytoplasm [15]. Consequently, we hypothesize that partial phenotypic 


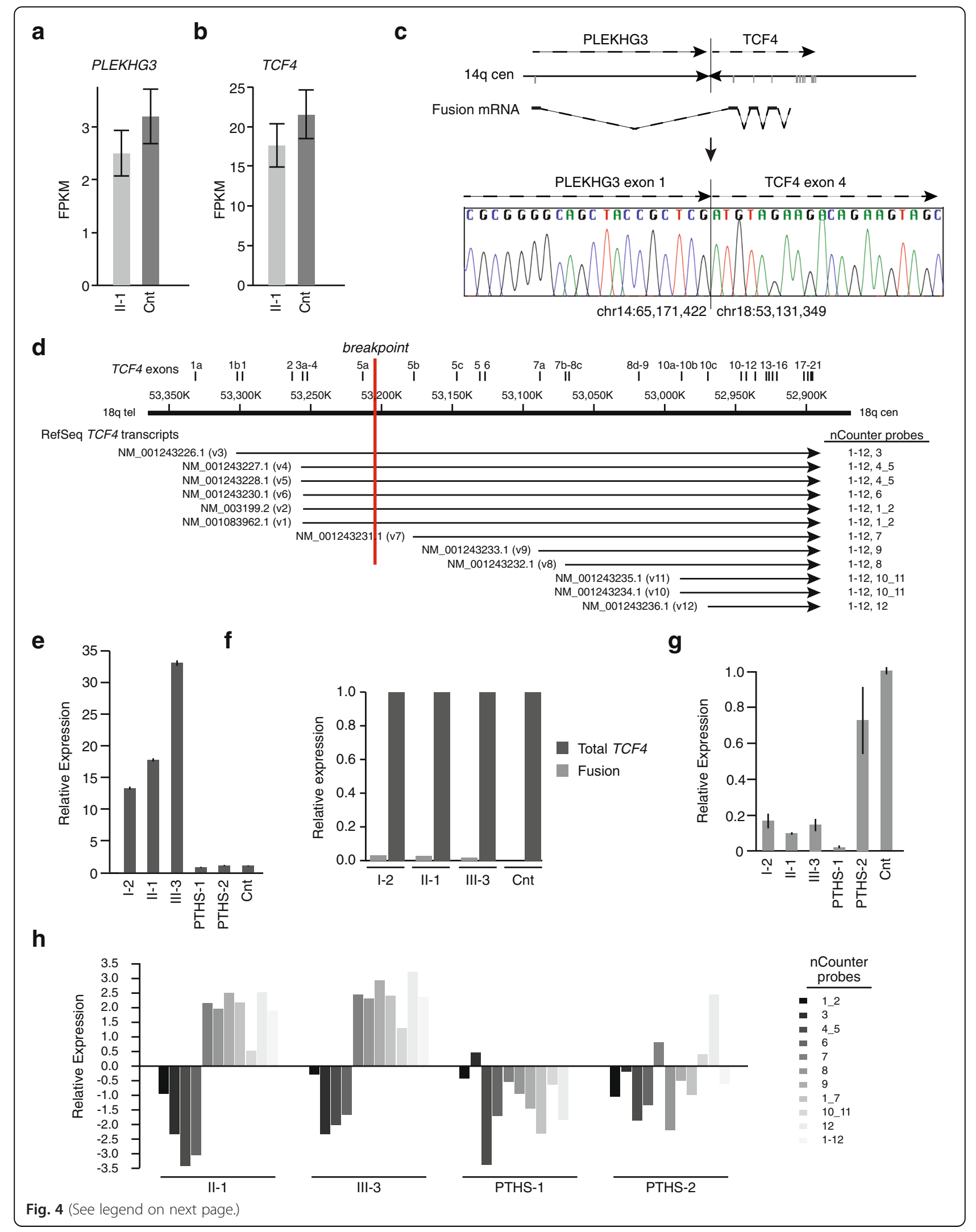




\begin{abstract}
(See figure on previous page.)
Fig. 4 Analysis of expression of genes at the breakpoints, i.e., PLEKHG3 and TCF4. (a) Graph comparing PLEKHG3 expression between cultured skin fibroblasts of individual II-1 and cultured skin fibroblasts of an unaffected control. Analysis was done by quantitation of transcriptome sequence reads and is shown as fragments per kilobase of exon per million fragments mapped (FPKM). (b) Graph comparing combined levels of all TCF4 transcript variants between cultured skin fibroblasts of individual II-1 and cultured skin fibroblasts of an unaffected control. Analysis was done by quantitation of transcriptome sequence reads. (c) Figure showing the PLEKHG3 : TCF4 fusion transcript generated by the derivative chromosome 14. The first non-coding exon of PLEKHG3 ( $3^{\prime}$ end chr14:65,171,422) is spliced to a coding exon of TCF4 $\left(5^{\prime}\right.$ end chr18:53,131,349). This coding exon is incorporated into TCF4 transcripts NM_001243227.1, NM_001243226.2, NM_001243228.1, NM_001083962.1, NM_001243230.1, and NM_003199.2. Transcriptome sequencing detected the fusion transcript in cultured skin fibroblasts (data not shown) and RT-PCR and Sanger sequencing detected it in peripheral blood. (d) Diagram showing the 12 TCF4 RefSeq transcripts aligned to chromosome 18 as annotated in GRCh37/hg19. Physical positions and TCF4 exons along chromosome 18 are shown at the top; the exons are labeled as per Sepp et al. [15]. The breakpoint within TCF4 is shown in red. The transcript variant number is shown in parentheses following each RefSeq accession number. nCounter probes detecting each transcript are shown in the right-hand column. (e) Graph showing the composite mRNA level of all 12 TCF4 transcripts in the peripheral blood among individuals II-1, I-2, III-3, two individuals with Pitt-Hopkins Syndrome (PTHS) and pooled unaffected controls. Measurement was done by qRT-PCR. (f) Graph comparing the level of PLEKHG3 : TCF4 fusion mRNA to the composite mRNA level of all 12 TCF4 transcripts in the peripheral blood of individuals II-1, I-2, III-3, and pooled unaffected controls. Measurement was done by qRT-PCR. (g) Graph comparing the mRNA level in peripheral blood for transcripts interrupted by the translocation (NM_001243226.1, NM_001243227.1, NM_001243228.1, NM_001243230.1, NM_003199.2, NM_001083962.1) inclusive of the PLEKHG3-TCF4 fusion transcript. The mRNA levels were measured among individuals II-1, I-2, III-3, two individuals with Pitt-Hopkins Syndrome (PTHS) and pooled unaffected controls by qRT-PCR. (h) Graph comparing mRNA levels in peripheral blood for various TCF4 transcripts as assessed by nCounter Analysis. The mRNA levels were measured for individuals II-1 and III-3, two individuals with Pitt-Hopkins Syndrome (PTHS) and pooled unaffected controls. The transcripts detected by each nCounter probe are defined in panel $\mathbf{d}$
\end{abstract}

rescue from PTHS to mild ID occurs by increased expression of TCF4 isoforms localizing to the nucleus. Supporting this, point mutations associated with PTHS generally occur within or downstream of the NLS, whereas point mutations associated with mild ID generally occur upstream of the NLS [30, 47, 48]. An exception to this generalization is the mutation NM_001083962:c.[C469T];[=] (p.R157*) that alters the first amino acid of the NLS and can cause either mild ID or PTHS [47, 49]. We must acknowledge that expression profile of TCF4 in brain may differ from that in other tissues and that a potential shortcoming of our study, as well that of many others, is reliance on expression analysis of blood and skin fibroblasts.

Besides delineating a minimal set of mutated transcripts for occurrence of PTHS, the translocations in our patients and the individual reported by Kalscheuer et al. [43] show that biallelic expression for all TCF4 transcripts is essential for full intellectual function. The diminution of longer TCF4 isoforms is not rescued by increased expression of the shorter isoforms. This raises at least three possible disease mechanisms for consideration: 1) AD1, which is encoded only in the longer transcripts, is essential for full neural function of TCF4;2) the longer transcripts have promoters preferentially active in neural tissues; and 3) the overexpression of shorter isoforms induces mild ID. Supporting the first, AD1 and AD2 act synergistically for transcriptional activation compared to AD1 or AD2 alone [15]. Minimizing the likelihood of the second, although not excluding it, transcripts initiating at the exon 10 promoters, not those initiating proximal to exon 8 , are those most highly expressed in studied brain regions [15]. Supporting the third, a gain-of-function disease mechanism is consistent with prior studies of PTHS-associated TCF4 mutations
[30]. We conclude therefore that both gain- and loss-offunction mechanisms might contribute to TCF4-associated mild ID caused by chromosomal translocation and that expression of the full complement of TCF4 transcripts at the appropriate dosage is required for full intellectual function.

Related to the role of TCF4 for maintenance of intellectual function and variability of expressivity within a family, the three generations described herein provide some insight. All three affected individuals had similar intellectual disability suggesting minimal variation in expressivity. Also, the absence of early cognitive decline in the adult individuals suggests that TCF4 dysfunction is most detrimental during early brain development.

\section{Conclusions}

In summary, this study of a TCF4 translocation and its consequence on TCF4 promoter usage and fusion transcript expression provides insight into the relative roles of TCF4 isoforms in ID, highlights the potential for some TCF4 isoforms to partially rescue the dysmorphisms and ID characteristic of PTHS, shows that the ID phenotype associated with TCF4 mutation can be relatively consistent over generations and from childhood through adulthood. Validation of these observations in other patients is, however, required.

\section{Availability of supporting data}

The transcriptome data set supporting the results of this article are available in GEO repository, series record GSE77742 (http://www.ncbi.nlm.nih.gov/geo/ query/acccgi?acc $=$ GSE77742).

\section{Ethics, consent and permissions}

The family described herein gave consent to study participation. 


\section{Additional files}

Additional file 1: Supplementary Methods, Tables and Figures. (PDF 2983 kb)

Additional file 2: Read summary statistics of whole-genome sequencing on Illumina HiSeq 2000 (>Q20). (XLSX 56 kb)

Additional file 3: CASAVA human reference sequence (hg19) coverage summary of whole genome library. (XLSX $51 \mathrm{~kb}$ )

\section{Abbreviations}

AD1: transcription activation domain 1; AD2: transcription activation domain 2; bHLH: basic helix-loop-helix; bp: base pairs; CCDC68: coiled-coil domain containing 68; CDPred: Conserved Domain-based Prediction; CNS: central nervous system; DYNAP: dynactin associated protein; FPKM: fragments per kilobase of exon per million fragments mapped; HASH1: achaete-scute family bHLH transcription factor 1; ID: intellectual disability; Kb: kilobases; Math1: atonal bHLH transcription factor 1; Mb: megabases; neuroD2: neuronal differentiation 2; NLS: nuclear localization signal; Olig2: oligodendrocyte lineage transcription factor 2; PLEKHG3: pleckstrin homology domain containing, family G; PolyPhen2: Polymorphism Phenotyping v2; PTHS: Pitt-Hopkins syndrome; RAB27B: RAB27B, member RAS oncogene family; RefSeq: NCBI Reference Sequence Database; RNASeq: RNA sequencing; SNV: single nucleotide variant; TCF4: transcription factor 4

\section{Competing interests}

The authors declare that they have no competing interests.

\section{Authors' contributions}

VM, BNP, PFC, PA, CdS, RR, ML, DRA, SSB, PE, AEL, AL, MCM, CEM, MM, JCM, $A S, C V K, P S, W A G, C T, C F B$ made substantial contributions to conception and design, or acquisition of data, or analysis and interpretation of data. VM, BNP, PFC, PA, CdS, RR, ML, DRA, SSB, PE, AEL, AL, MCM, CEM, MM, JCM, AS, CVK, $P S, W A G, C T, C F B$ involved in drafting the manuscript or revising it critically for important intellectual content. VM, BNP, PFC, PA, CdS, RR, ML, DRA, SSB, $P E, A E L, A L, M C M, C E M, M M, J C M, A S, C V K, P S, W A G, C T, C F B$ have given final approval of the version to be published. VM, BP, CdS, RR, DA, CFB, WAG agree to be accountable for all aspects of the work in ensuring that questions related to the accuracy or integrity of any part of the work are appropriately investigated and resolved. All authors read and approved the final manuscript.

\section{Acknowledgements}

The authors thank Dr. Jan Friedman for critical review of this manuscript. This work was supported in part by the Intramural Research Program of the National Human Genome Research Institute and the Common, Fund, Office of the Director (NIH, Bethesda, Maryland). This work was supported in part by the Scottish Rite Foundation (C.D.S.), a Child and Family Research Institute Establishment Award (C.F.B.), and the Clinical Genomics Platform of the Michael Smith Foundation for Health Research (P.A.). For C.E.M. we would to like to thank the Bert L. and N. Kuggie Vallee Foundation, the Irma T. Hirschl and Monique Weill-Caulier Charitable Trusts, the WorldQuant Foundation, the Pershing Square Sohn Prize, the STARR Consortium (I7-A765, 19-A9-071), and support from the National Institutes of Health (R01NS076465).

\section{Author details}

${ }^{1} \mathrm{NIH}$ Undiagnosed Diseases Program, Common Fund, Office of the Director, National Institutes of Health, Bethesda, MD, USA. ${ }^{2}$ Department of Medical Genetics, University of British Columbia, Children's and Women's Health Centre of BC, Vancouver, BC, Canada. ${ }^{3}$ Child and Family Research Institute, University of British Columbia, Vancouver, BC, Canada. ${ }^{4}$ Sunny Hill Health Centre for Children, Vancouver, BC, Canada. ${ }^{5}$ Department of Molecular and Human Genetics, Baylor College of Medicine, Houston, TX, USA. ${ }^{6}$ Department of Pathology and Laboratory Medicine, University of British Columbia, Vancouver, BC, Canada. ${ }^{7}$ Department of Physiology and Biophysics, Weill Cornell Medical College, New York, NY, USA. ${ }^{8}$ The HRH Prince Alwaleed Bin Talal Bin Abdulaziz Alsaud Institute for Computational Biomedicine, New York, NY, USA. 'The Feil Family Brain and Mind Research Institute (BMRI), New York, NY, USA. ${ }^{10} \mathrm{NIH}$ Intramural Sequencing Center, National Human Genome Research Institute, National Institutes of Health, Bethesda, MD, USA.
${ }^{11}$ Department of General Practice, Faculty of Medicine, University of British Columbia, Vancouver, BC, Canada. ${ }^{12} \mathrm{NHGRI}$, National Institutes of Health, Bethesda, MD, USA.

Received: 15 February 2016 Accepted: 25 April 2016

Published online: 14 May 2016

\section{References}

1. Luckasson R et al. Mental Retardation: Definition, Classification, and Systems of Supports 10. Washington, DC: The American Association on Intellecutal and Developmental Disabilitites; 2002

2. Aicardi J. The etiology of developmental delay. Semin Pediatr Neurol. 1998;5(1):15-20.

3. Larson SA et al. Prevalence of mental retardation and developmental disabilities: estimates from the 1994/1995 national health interview survey disability supplements. Am J Ment Retard. 2001;106(3):231-52.

4. Roeleveld N, Zielhuis GA, Gabreels F. The prevalence of mental retardation: a critical review of recent literature. Dev Med Child Neurol. 1997;39(2):125-32.

5. Ropers HH, Hamel BC. X-linked mental retardation. Nat Rev Genet. 2005:6(1):46-57.

6. Froyen $\mathrm{G}$ et al. X-linked mental retardation and epigenetics. J Cell Mol Med. 2006;10(4):808-25.

7. Sherr EH, Shevell MI. In: Swaiman KF, Ashwal S, Ferriero DM, editors. Mental Retardation and Global Developmental Delay, in Pediatric Neurology: Principles and Practice. Philadelphia: Mosby; 2006. p. 799-820.

8. Norman MG et al. Congenital Malformations of the Brain. New York: Oxford University Press; 1995.

9. Walsh T et al. Rare structural variants disrupt multiple genes in neurodevelopmental pathways in schizophrenia. Science. 2008;320(5875):539-43.

10. Day JJ, Sweatt JD. Epigenetic mechanisms in cognition. Neuron. 2011;70(5): 813-29.

11. Jakovcevski M, Akbarian S. Epigenetic mechanisms in neurological disease. Nat Med. 2012;18(8):1194-204.

12. Mehler MF. Epigenetics and the nervous system. Ann Neurol. 2008;64(6):602-17

13. van Bokhoven $\mathrm{H}$. Genetic and epigenetic networks in intellectual disabilities. Annu Rev Genet. 2011:45:81-104.

14. Yoo AS, Crabtree GR. ATP-dependent chromatin remodeling in neural development. Curr Opin Neurobiol. 2009:19(2):120-6.

15. Sepp $M$ et al. Functional diversity of human basic helix-loop-helix transcription factor TCF4 isoforms generated by alternative $5^{\prime}$ exon usage and splicing. PLoS One. 2011;6(7):e22138.

16. Ravasi T et al. An atlas of combinatorial transcriptional regulation in mouse and man. Cell. 2010;140(5):744-52.

17. Navarrete K et al. TCF4 (e2-2; ITF2): a schizophrenia-associated gene with pleiotropic effects on human disease. Am J Med Genet B Neuropsychiatr Genet. 2013;162(1):1-16.

18. Ross SE, Greenberg ME, Stiles CD. Basic helix-loop-helix factors in cortical development. Neuron. 2003;39(1):13-25

19. Flora A et al. The E-protein Tcf4 interacts with Math1 to regulate differentiation of a specific subset of neuronal progenitors. Proc Natl Acad Sci U S A. 2007:104(39):15382-7.

20. Gohlke JM et al. Characterization of the proneural gene regulatory network during mouse telencephalon development. BMC Biol. 2008;6:15.

21. Persson $\mathrm{P}$ et al. HASH-1 and E2-2 are expressed in human neuroblastoma cells and form a functional complex. Biochem Biophys Res Commun. 2000;274(1):22-31.

22. Ravanpay AC, Olson JM. E protein dosage influences brain development more than family member identity. J Neurosci Res. 2008;86(7):1472-81.

23. Einarson MB, Chao MV. Regulation of Id 1 and its association with basic helix-loop-helix proteins during nerve growth factor-induced differentiation of PC12 cells. Mol Cell Biol. 1995;15(8):4175-83.

24. Fu H et al. A genome-wide screen for spatially restricted expression pattern identifies transcription factors that regulate glial development. J Neurosci. 2009;29(36):11399-408

25. Othman A et al. Olig1 is expressed in human oligodendrocytes during maturation and regeneration. Glia. 2011:59(6):914-26.

26. Panman $L$ et al. Transcription factor-induced lineage selection of stem-cell-derived neural progenitor cells. Cell Stem Cell. 2011;8(6):663-75. 
27. Brockschmidt A et al. Severe mental retardation with breathing abnormalities (Pitt-Hopkins syndrome) is caused by haploinsufficiency of the neuronal bHLH transcription factor TCF4. Hum Mol Genet. 2007;16(12):1488-94.

28. Zweier C et al. Haploinsufficiency of TCF4 causes syndromal mental retardation with intermittent hyperventilation (Pitt-Hopkins syndrome) Am J Hum Genet. 2007;80(5):994-1001.

29. Amiel J et al. Mutations in TCF4, encoding a class I basic helix-loop-helix transcription factor, are responsible for Pitt-Hopkins syndrome, a severe epileptic encephalopathy associated with autonomic dysfunction. Am J Hum Genet. 2007;80(5):988-93.

30. Sepp M, Pruunsild P, Timmusk T. Pitt-Hopkins syndrome-associated mutations in TCF4 lead to variable impairment of the transcription factor function ranging from hypomorphic to dominant-negative effects. Hum Mol Genet. 2012;21(13):2873-88.

31. Rosenfeld JA et al. Genotype-phenotype analysis of TCF4 mutations causing Pitt-Hopkins syndrome shows increased seizure activity with missense mutations. Genet Med. 2009;11(11):797-805.

32. Whalen $\mathrm{S}$ et al. Novel comprehensive diagnostic strategy in Pitt-Hopkins syndrome: clinical score and further delineation of the TCF4 mutational spectrum. Hum Mutat. 2012;33(1):64-72.

33. Wang $\mathrm{K}$ et al. PennCNV: an integrated hidden Markov model designed for high-resolution copy number variation detection in whole-genome SNP genotyping data. Genome Res. 2007;17(11):1665-74.

34. Trapnell C, Pachter L, Salzberg SL. TopHat: discovering splice junctions with RNA-Seq. Bioinformatics. 2009;25(9):1105-11.

35. Trapnell $\mathrm{C}$ et al. Differential gene and transcript expression analysis of RNAseq experiments with TopHat and Cufflinks. Nat Protoc. 2012;7(3):562-78.

36. Trapnell $\mathrm{C}$ et al. Differential analysis of gene regulation at transcript resolution with RNA-seq. Nat Biotechnol. 2013;31(1):46-53.

37. Harewood $L$ et al. The effect of translocation-induced nuclear reorganization on gene expression. Genome Res. 2010;20(5):554-64.

38. Munoz A, Sankoff D. Detection of gene expression changes at chromosomal rearrangement breakpoints in evolution. BMC Bioinformatics. 2012;13 Suppl 3:S6.

39. Spellman PT, Rubin GM. Evidence for large domains of similarly expressed genes in the Drosophila genome. J Biol. 2002;1(1):5.

40. Rybarczyk-Filho JL et al. Towards a genome-wide transcriptogram: the Saccharomyces cerevisiae case. Nucleic Acids Res. 2011;39(8):3005-16.

41. Johnston JJ et al. Massively parallel sequencing of exons on the $X$ chromosome identifies RBM10 as the gene that causes a syndromic form of cleft palate. Am J Hum Genet. 2010:86(5):743-8.

42. Adzhubei, I., D.M. Jordan, and S.R. Sunyaev, Predicting functional effect of human missense mutations using PolyPhen-2, in Current protocols in human genetics, J.L. Haines, et al., Editors. 2013, John Wiley \& Sons, Inc. p. $7.20 .1-7.20 .41$

43. Kalscheuer VM et al. Disruption of the TCF4 gene in a girl with mental retardation but without the classical Pitt-Hopkins syndrome. Am J Med Genet A. 2008;146A(16):2053-9.

44. Marangi $\mathrm{G}$ et al. Proposal of a clinical score for the molecular test for Pitt-Hopkins syndrome. Am J Med Genet A. 2012;158A(7):1604-11.

45. Marangi $G$ et al. The Pitt-Hopkins syndrome: report of 16 new patients and clinical diagnostic criteria. Am J Med Genet A. 2011;155A(7):1536-45.

46. Schluth-Bolard $C$ et al. Breakpoint mapping by next generation sequencing reveals causative gene disruption in patients carrying apparently balanced chromosome rearrangements with intellectual deficiency and/or congenital malformations. J Med Genet. 2013:50(3):144-50.

47. Hamdan FF et al. Parent-child exome sequencing identifies a de novo truncating mutation in TCF4 in non-syndromic intellectual disability. Clin Genet. 2013;83(2):198-200.

48. Rauch A et al. Range of genetic mutations associated with severe non-syndromic sporadic intellectual disability: an exome sequencing study. Lancet. 2012;380(9854):1674-82.

49. Zweier $\mathrm{C}$ et al. Further delineation of Pitt-Hopkins syndrome: phenotypic and genotypic description of 16 novel patients. J Med Genet. 2008:45(11):738-44.

50. Andrieux J et al. Deletion 18q21.2q21.32 involving TCF4 in a boy diagnosed by CGH-array. Eur J Med Genet. 2008;51(2):172-7.

51. de Pontual $L$ et al. Mutational, functional, and expression studies of the TCF4 gene in Pitt-Hopkins syndrome. Hum Mutat. 2009;30(4):669-76.
52. Giurgea I et al. TCF4 deletions in Pitt-Hopkins syndrome. Hum Mutat. 2008:29(11):E242-51.

53. Inati $\mathrm{A}$ et al. A case of Pitt-Hopkins syndrome with absence of hyperventilation. J Child Neurol. 2013;28(12):1698-701.

54. Kato $Z$ et al. Interstitial deletion of 18q: comparative genomic hybridization array analysis of 46, XX, del(18)(q21.2.q21.33). Birth Defects Res A Clin Mol Teratol. 2010;88(2):132-5.

55. Kousoulidou L et al. $263.4 \mathrm{~kb}$ deletion within the TCF4 gene consistent with Pitt-Hopkins syndrome, inherited from a mosaic parent with normal phenotype. Eur J Med Genet. 2013;56(6):314-8.

56. Lehalle $D$ et al. Fetal pads as a clue to the diagnosis of Pitt-Hopkins syndrome. Am J Med Genet A. 2011;155A(7):1685-9.

57. Stavropoulos DJ, MacGregor DL, Yoon G. Mosaic microdeletion 18q21 as a cause of mental retardation. Eur J Med Genet. 2010;53(6):396-9.

58. Taddeucci $\mathrm{G}$ et al. Pitt-Hopkins syndrome: report of a case with a TCF4 gene mutation. Ital J Pediatr. 2010;36:12.

59. Takano K et al. Two percent of patients suspected of having Angelman syndrome have TCF4 mutations. Clin Genet. 2010;78(3):282-8.

60. Takano K et al. Pitt-Hopkins syndrome should be in the differential diagnosis for males presenting with an ATR-X phenotype. Clin Genet. 2011;80(6):600-1.

61. Takenouchi T et al. Tissue-limited ring chromosome 18 mosaicism as a cause of Pitt-Hopkins syndrome. Am J Med Genet A. 2012;158A(10):2621-3.

\section{Submit your next manuscript to BioMed Central and we will help you at every step:}

- We accept pre-submission inquiries

- Our selector tool helps you to find the most relevant journal

- We provide round the clock customer support

- Convenient online submission

- Thorough peer review

- Inclusion in PubMed and all major indexing services

- Maximum visibility for your research

Submit your manuscript at www.biomedcentral.com/submit

) Biomed Central 